\title{
Study and Review of Helium Gas Turbine Technology for High-temperature Pre-cooler Gas
}

\author{
Suhayb Lateef Sadaa, \\ PhD in Technical Sciences, Associate Professor Tseligorov preparation, \\ Don State Technical University (DSTU) Rostov on Don, Russia
}

Doi:10.19044/esj.2019.v15n21p80 ～URL:http://dx.doi.org/10.19044/esj.2019.v15n21p80

\begin{abstract}
The technology of pre-cooler system is the strongest means of air cooling and heat exchangers in the world. Heat exchangers that cool the incoming air are the biggest technical challenge At Mach 5 (5 times the speed of sound), To meet this challenge, REL (Reaction Engines Ltd) is a UK-based company, has developed the most powerful lightweight heat exchangers in the world -.The air enters the radiator to a compressor such as the jet engine, and it is pre-cooled from $1,000^{\circ} \mathrm{C}$ to minus $150^{\circ} \mathrm{C}$, in $1 / 100$ th of a second, displacing 400 Mega-Watts of heat energy (equivalent to the power output of a typical gas-powered power station) yet weighs less than 11/4 tons . Equivalent to a small power plant, a very high rate in the world of aviation. As the temperature inside the engine will decrease significantly, this will help the engine to continue to work normally and thus increase its speed comfortably. The pre-cooled cooling device weighs about a ton, which is a group of thin tubes that contain helium (helium condensate) in their liquid form. These pipes are intertwined with each other in spiral form. This device absorbs heat and air cooled to $150{ }^{\circ} \mathrm{C}$ below zero before entering the engine. With rising fuel costs there is an initiative to conserve fuel during flight. The breakthrough achieved will allow heat exchangers to be used for a whole range of new applications.
\end{abstract}

Keywords: Helium gas system, helium turbine, turbine technology, Hightemperature, pre-cooler gas, thermal power, thermodynamic power, air conditioning system, aircraft, heat exchangers cycle, reaction engine, heat transfer

\section{Introduction}

Helium is an inert gas that is non-corrosive and does not become radioactive. The cycle efficiency has a theoretical advantage owing to the high specific heat ratio of helium. The choice of working fluid significantly 
influences not only the cycle efficiency but also the system compactness. Additionally, the heat exchanger design also is advantageous because the thermal conductivity and heat transfer coefficient for helium are higher than those for air. On the other hand, helium leakage could easily occur due to its low molecular weight and thus reliable sealing of the system is imperative [IAEA-TECDOC-899,1995]. The fluid properties of helium strongly influence the size, geometries, and performance of gas turbine. High pressure operation is needed to achieve a compact power [A.R. Howell and W.J. Calvert, 1978, T. Takizuka, S. Takata, 2004]. The British company Reaction Engines Limited has recently announced that it has developed an aircraft engine that can drive an aircraft carrying 300 passengers to anywhere on the ground in as little as four hours. An aircraft with this engine can travel from Europe to Australia in two to four hours instead of 22 hours at the moment. Surprisingly, this engine can also drive aircraft into outer space. The British company Reaction Engines has announced that two prototype models of two SABRE engines will be issued, the first is the LAPCAT A2, a civilian aircraft that can carry 300 passengers and travel from Europe to Australia in two to four hours. "This aircraft can fly around the Earth at speeds up to Mach 5, which is about five times the speed of sound," says engineer Alan Bond, project engineer. The second plane, SKYLON, is an aircraft in its shape and a spacecraft in terms of its work. It is an unmanned aircraft with a length of about 82 meters. Although it flies like a rocket in space, it takes off and lands horizontally like any ordinary aircraft, making it usable more than once. SABRE - Synergetic Air Breathing Rocket Engine - is a new class of engine for propelling both high speed aircraft and spacecraft. SABRE engines are unique in delivering the fuel efficiency of a jet engine with the power and high speed ability of a rocket. Unlike jet engines, which are only capable of powering a vehicle up to Mach 3, three times the speed of sound, SABRE engines are capable of Mach 5.4 in air-breathing mode, and Mach 25 in rocket mode for space flight. They are simply going to revolutionised the way we travel around the globe, and into orbit. Like jet engines, SABRE can be scaled in size to provide difference levels of thrust for different applications which is crucial to our success - it's going to enable a whole generation of air and space vehicles.

\section{Overview of the main parts of the engine for pre-cooler system:}

SABRE is a precooled, hybrid air-breathing/rocket engine that burns liquid hydrogen fuel combined with an oxidant of either compressor-fed gaseous air from the atmosphere, or stored liquid oxygen fed using a turbopump , precooler reduce air temperature from $(+1800 \mathrm{C} 0$ to $-150 \mathrm{C} 0)$ ,from runway takeoff to burn with its liquid hydrogen fuel. Once the air becomes too thin, engine switches to its onboard liquid oxygen tanks. This 
saves engine from having to carry more liquid oxygen than absolutely necessary [Webber, H., Feast, S. and Bond, A,2008, SKYLON 2011] as shown in Figure 1.

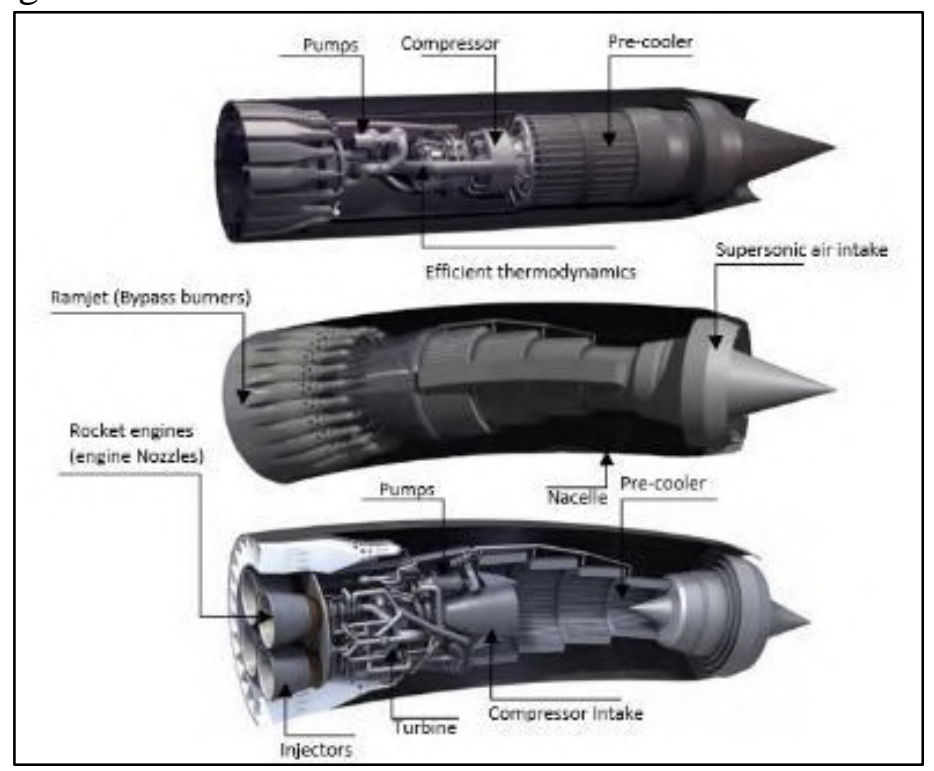

Fig. 1. main parts of the engine

Table.1 Reaction Engines

\begin{tabular}{|l|}
\hline Reaction Engines SABRE \\
\hline Designed by: Reaction Engines Limited (United Kingdom) \\
\hline Application: Single-stage-to-orbit \\
\hline Associated L/V: Skylon \\
\hline Predecessor: RB545 \\
\hline Status: Development \\
\hline Liquid-fueled hybrid engine \\
\hline Propellant: Air/LO2 / Liquid hydrogen \\
\hline Cycle: combined cycle precooled jet engine + closed cycle rocket engine \\
\hline Performance \\
\hline Thrust (Vac.): $~ 1,800 \mathrm{kN}$ \\
\hline Thrust (SL): $\sim 1,350 \mathrm{kN}$ \\
\hline Thrust-to-weight ratio: up to 14 (atmospheric) \\
\hline Isp (Vac.): $460 \mathrm{~s}$ \\
\hline Isp (SL): $3600 \mathrm{~s}$ \\
\hline
\end{tabular}




\begin{tabular}{|c|c|c|c|c|c|}
\hline \multicolumn{6}{|c|}{ NOTATION } \\
\hline \multicolumn{3}{|c|}{ Symbols: } & $\mathrm{T}$ & Temperature & $\mathrm{K}$ \\
\hline \multirow{2}{*}{$\begin{array}{l}\mathrm{A} \\
\mathrm{C} \\
\mathrm{F}\end{array}$} & Heat transfer surface area & $\mathrm{m}^{2}$ & $\Delta \mathrm{T}_{\ln }$ & Logarithmic mean temperature & $\mathrm{K}$ \\
\hline & Capacity rate & $\mathrm{W} / \mathrm{K}$ & & difference & \\
\hline $\mathrm{F}$ & $\begin{array}{l}\text { Correction factor to rate of hea } \\
\text { transfer equation }\end{array}$ & & $\mathrm{U}$ & $\begin{array}{l}\text { Overall heat transfer } \\
\text { coefficient }\end{array}$ & $\mathrm{W} /(\mathrm{m} 2 \mathrm{~K})$ \\
\hline$h$ & Specific enthalpy & $\mathrm{J} / \mathrm{kg}$ & $\Delta \mathrm{V}$ & Separation velocity & $\mathrm{m} / \mathrm{s}$ \\
\hline$h^{*}$ & Heat transfer coefficient $\quad V$ & $\mathrm{~W} /\left(\mathrm{m}^{2} \mathrm{~K}\right)$ & Gree & etters: & \\
\hline $\mathrm{I}_{\mathrm{sp}}$ & Specific Impulse & & $\gamma$ & Ratio of specific heats & \\
\hline$k$ & Tube thermal conductance & $\mathrm{W} / \mathrm{mK}$ & $\eta K E$ & Intake kinetic energy efficiency & \\
\hline $\mathrm{K}$ & Capacity rate ratio & & Subs & pts: & \\
\hline $\mathrm{m} \cdot$ & Mass flow rate & $\mathrm{kg} / \mathrm{s}$ & $a$ & Air & \\
\hline$M$ & Mach number & & $c$ & Cycle & \\
\hline$P$ & Pressure & $\mathrm{N} / \mathrm{m}^{2}$ & $f$ & Final & \\
\hline $\mathrm{Q}^{\bullet}$ & Rate of heat transfer & W & $h$ & Hydrogen & \\
\hline$S_{\text {gen }}$ & Total cycle entropy generation & $\mathrm{J} / \mathrm{K}$ & he & Helium & \\
\hline$S$ & Specific entropy & $\mathrm{J} /(\mathrm{kgK})$ & $i$ & Initial & \\
\hline$t$ & Tube thickness & $\mathrm{m}$ & $o$ & Total & \\
\hline & & & & Recovered & \\
\hline & & & ref & Reference & \\
\hline
\end{tabular}

Supersonic air intake: At the front of the engine a simple translating axisymmetric shock cone inlet slows down the airstream to subsonic speeds using just two shock reflections. Air Intake Two-dimensional bifurcated intake is selected. Required capture area greatly changes, since the flight Mach number varies from 0 to 5 . The capture area is adjusted by varying the angle of the cowl. Maximum capture area is decided by front face area of the precooling heat exchanger. [Haselbacher, H.1978]. The largest component of the program is the precooler development. This will involve manufacture of a precooler module. A representative pre-cooler will be installed upstream of a jet-engine to simulate realistic operational conditions including the effectiveness of the frost control.( Frost control is required on the pre-cooled engine as humidity in the air will otherwise condense and freeze in the sudden temperature drop and the resulting ice formation can block the intake flow path rapidly) Tests of ambient air must be performed in different relative humidity in order to demonstrate control of frost accumulation by pre-coolant. [Webber, H., Feast, S. and Bond, A.2008]. As in Figure 2. 


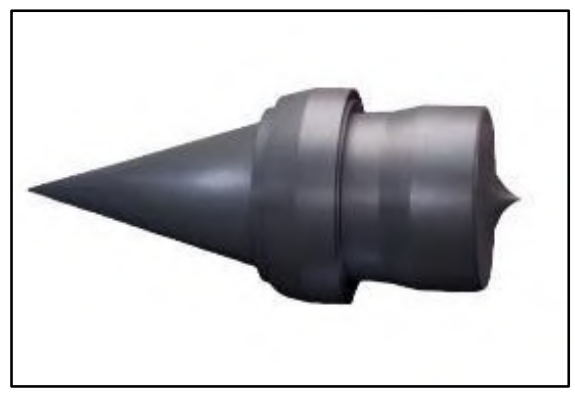

Fig. 2. Supersonic air intake

Pre-cooling Heat Exchanger: Two-dimensional pre-cooling heat exchanger is obliquely installed in a subsonic diffuser. The flow velocity of the air is set as $25 \sim 30 \mathrm{~m} / \mathrm{s}$. The heat exchanger is made with the shell and tube system with fins. During flight air enters the pre-cooler. In 1/100th of a second a network of fine piping inside the pre-cooler drops the air's temperature by well over 100C. Very cold helium in the piping makes this possible. Cools the hot incoming air, keeping engine components cool at high speed $1,000 \mathrm{~K}$ temperature drop in $1 / 20^{\text {th }}$ second, unlocking new capabilities in hypersonic flight. [SKYLON,2011] As in Figure 3.

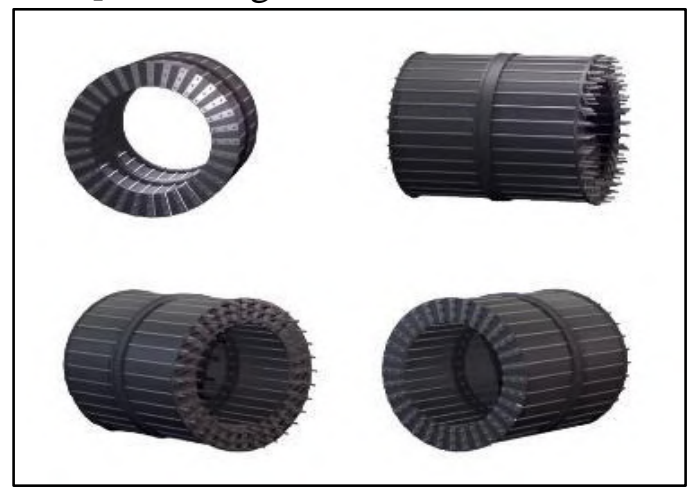

Fig. 3. Pre-cooling Heat Exchanger

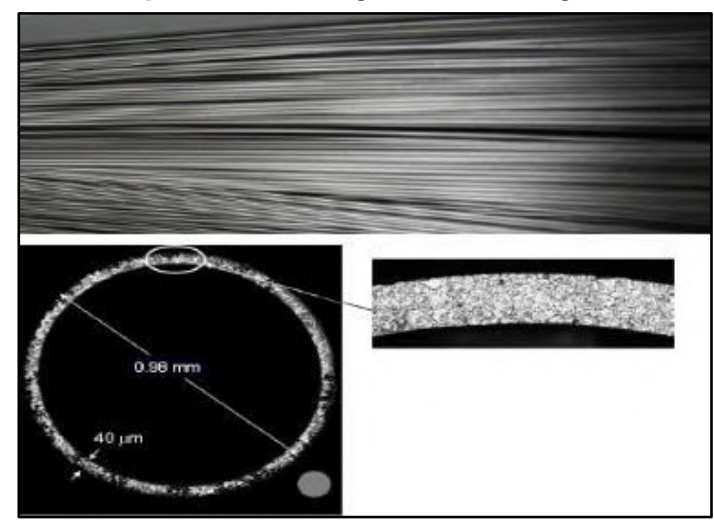

Fig. 4. Heat Exchanger Pipes 
The prototype pre-cooler will be made from over 16,000 thin-walled Inconel tubes. The tube's diameter $0,98 \mathrm{~mm}$, Thickness of tube $40 \mu \mathrm{m}$ as shown in Figure 4.

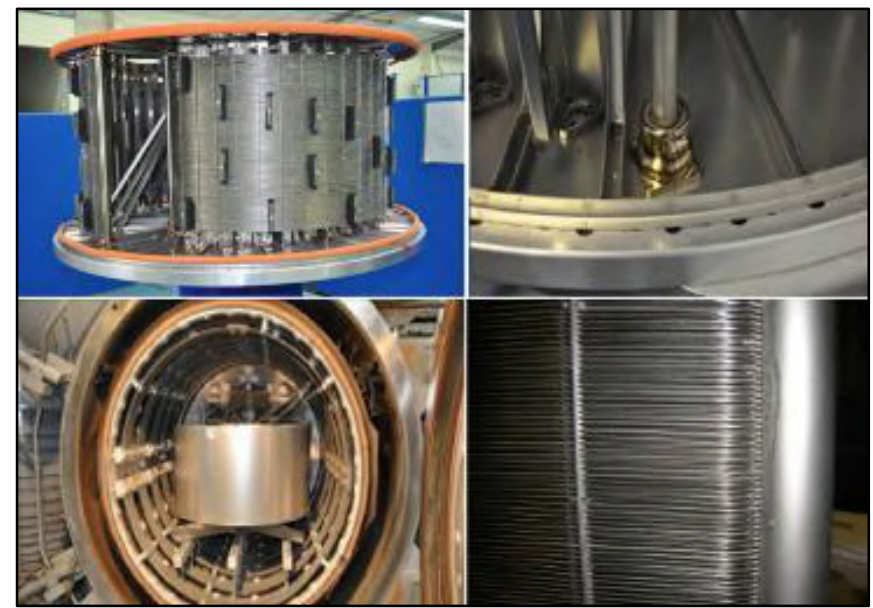

Fig. 5. Header tube

Header tube installation and a production module under construction, header / matrix tube brazed joints and vacuum brazing [Managing Director Dr. Alan Bond,2011] as shown in Figure 5.

Within any isolated system the entropy must increase or remain constant according to the second law of thermodynamics. An increase indicates a permanent loss of useful energy within the Cycle [G.L. Dugger,1968] Irreversibilities within a heat exchanger are caused by entropy rise due to heat transfer over a finite temperature difference and also that due to the pressure loss through the system. These must be minimised whilst achieving the required heat transfer rate using as small a heat transfer area as possible. The rate of heat transfer, $\mathrm{Q} \bullet$, per unit heat transfer area, A, between two fluids separated by a solid boundary can be expressed as:

$$
\frac{\dot{Q}}{A}=U \Delta T
$$

$\Delta \mathrm{T}$ : is some mean temperature difference between two fluids

Fluids exchanging heat, and $U$ is overall heat transfer coefficient. The reciprocal of $U$ is the overall thermal resistance of the heat exchanger and is expressed by:

$$
\frac{1}{U}=\frac{1}{h_{a}^{*}}+\frac{t}{k}+\frac{1}{h_{h e}^{*}}
$$


$\frac{1}{h_{a}^{*}}$ : is the air flow thermal resistance.

$\frac{1}{h_{h e}^{*}}:$ is the helium flow thermal resistance.

$\frac{t}{k} \quad$ : is the resistance of the separating solid surface where $\mathrm{t}$ is the

Since the conductance of the solid boundary is generally far greater than either of the fluid heat transfer coefficients, the overall heat transfer coefficient is controlled by the most thermally resistive fluid layer - the air in this case. In order to maximize.

$$
\frac{\stackrel{Q}{Q}}{A}
$$

We can enhance the heat transfer coefficient of the fluid layers by, for example, increasing the fluid flow velocity. For low density gaseous flow heat exchangers, however, an increase in flow velocity can have an overall negative effect on performance due to the much greater increase in frictional power loss. A very large heat transfer area is necessary in order to achieve the 400 MW power requirement at the Mach 5 design condition. This ultimately leads to a 'compact heat exchanger' design such that the heat exchanger volume does not become excessive, and where the 'compactness' or 'high surface area density' is achieved by reducing the diameter of the flow passages. It can be shown that extended heat transfer surfaces, i.e. in the form of fins on each of the flow channels, which do not help to contain the pressure differential, are not mass effective. Given the high internal pressure of the helium coolant, the flow channels must be of tubular form in order to minimise weight. The precooler configuration therefore consists of a compact array of small diameter circular tubes. Compactness in itself gives rise to improved heat transfer per unit area since the fluid heat transfer coefficient is inversely proportional to the tube diameter. Fluid flow heat transfer coefficients can also be increased by interrupting the surface boundary layers to prevent their growth in thickness. A cross flow arrangement of the precooler tubes therefore automatically forces new boundary layers to grow on each tube. [W.M. Kays and A.L. London,1998] $\Delta \mathrm{T}$ can be minimised firstly by introducing a counter flow design into the heat exchanger. Figure 6. 


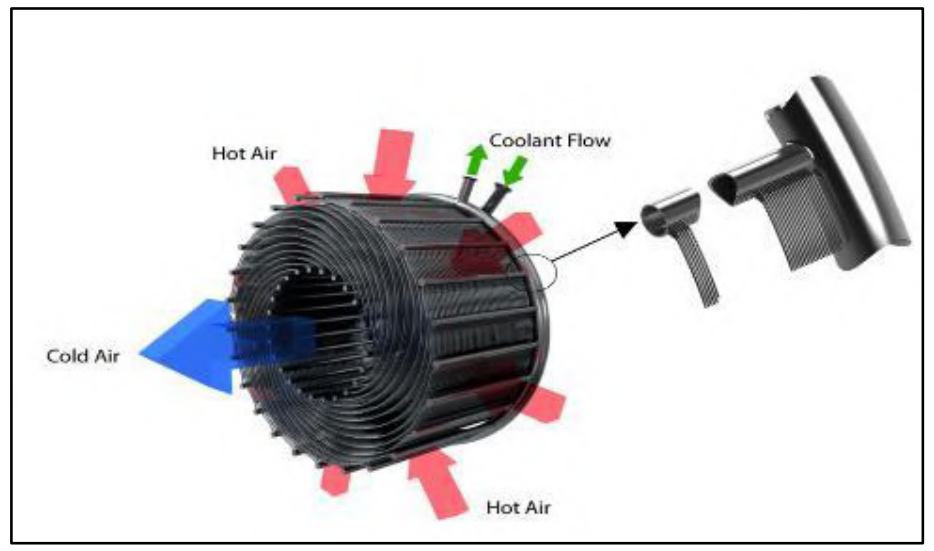

Fig. 6 The heat exchanger of precooler.

\section{Compressor Intake}

The compressor is made of titanium metal and is a Normal materials, as shown in Figure 7 Compressor exit pressure $(\mathrm{P})$ takes the maximum value (about 1.4MPa) at Mach 5. Compressor, Compressor inlet temperature rises over the design point in the Mach range between 2 and 3.5. However, compressor outlet temperature $(\mathrm{T})$ is below $600 \mathrm{~K}$ in the whole flight region.. The equivalence ratio is controlled to maintain fixed combustion temperature. Since axial compressor aero thermodynamic design techniques have been well documented, it is not the intent to describe detailed analyses in this paper, but rather to outline how the fluid properties of helium influence the flow path geometries, and to emphasize that the gas dynamic procedures used are essentially identical to conventional air-breathing gas turbine practice. The choice of working fluid affects the turbocompressor primarily in two ways: (1) the number of stages for the attainment of the required pressure ratio and high efficiency, and (2) the machine size for a high pressure closed system. The specific heat of helium is five times that of air, and since the stage temperature rise varies inversely as the specific heat (for a given limiting blade speed), it follows that the temperature rise available per stage when running with helium will be only one-fifth that of air, and this of course, results in more stages being required for a helium compressor. Substitution of helium for air greatly modifies aerodynamic requirements by removing Mach number limitations, the problem then becomes that of trying to induce the highest possible gas velocities that stress-limited blades will allow. For the selected machine configuration (i.e., single shaft with synchronous generator) the compressor rotational speed is, of course, fixed at $3600 \mathrm{rpm}$. The size of the machine is thus dictated by the choice of blade speed, there being an incentive to use the highest values commensurate with stress limits to reduce the number of stages, since the stage loading factor is inversely proportional to the square 
of the blade speed. , and an accepted upper limit for high efficiency compressors is about 0.90 . With high pressure helium. And at this early stage of design, have acceptable gas dynamic loading factors. [Taguchi, H. and Yanagi, R]

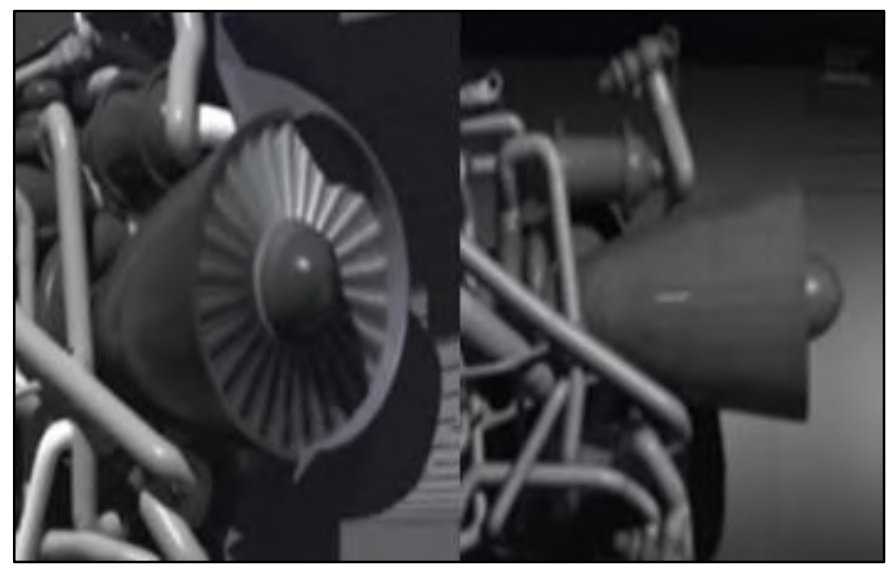

Fig. 7. Compressor Intake

A typical stage of an axial-flow compressor is shown in Fig. 8. Assuming the flow of a streamline that enters the rotor at one radius and leaves at another radius with another velocity, the change in angular momentum in passing the rotor produces an enthalpy increase [H.I.H. Saravanamuttoo, G.F.C. Rogers and H. Cohen,2001]. The process through the rotor and stator can be assumed to be adiabatic, and there is an increase in stagnation pressure only within the rotor and a decrease in the stagnation pressure in the stator due to fluid friction. By applying the steady flow energy equation to the rotor, the power input is given by

$$
P=\dot{m} C_{p}\left(T_{02}-T_{01}\right)
$$

There is no work input in the stator and thus the stagnation temperatures of positions 2 and 3 are the same. Fig. 9 shows the velocity vectors and associated velocity diagram for a typical stage. The fluid approaches the inlet of the rotor with a velocity $V_{1}$ at an angle $\alpha_{1}$ and the relative velocity $W_{1}$ at $\beta_{1}$ results from the blade speed $U$. The fluid is deflected through the rotor, and the fluid leaves the rotor with a relative velocity $W_{2}$ at $\beta_{2}$. Considering the blade speed, the velocity $V_{2}$ is given at an angle $\alpha_{2}$. The tangential velocities $V_{\theta 1}$ and $V_{\theta 2}$, are found from the meridional velocity $V_{m}$ and the flow angles, and these tangential velocities can produce a change in enthalpy through work transfer. An increase of total enthalpy is obtained from the Euler turbomachine equation along the streamlines as follows:

$$
\Delta h_{0}=\omega\left(r_{2} V_{\theta 2}-r_{1} V_{\theta 1}\right)
$$


Therefore, the power input to the stage can be expressed.

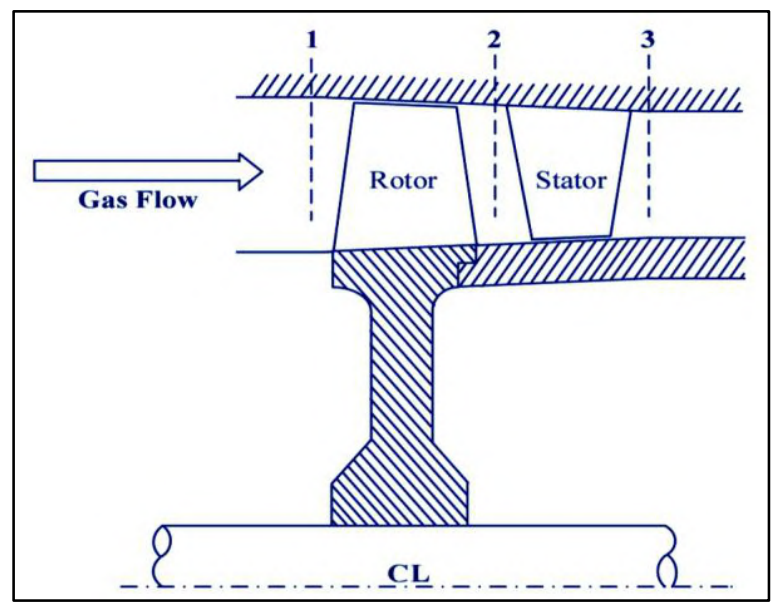

Fig. 8. Compressor flow Stage

As follows:

$$
P=\dot{m} \omega\left(r_{2} V_{\theta 2}-r_{1} V_{\theta 1}\right)
$$

This input energy is absorbed usefully in raising the pressure of the fluid, and the pressure rise is dependent on the efficiency of the compression process. The stage pressure ratio is given by

$$
\frac{p_{03}}{p_{01}}=\left[1+\frac{\eta_{S, C} \Delta h_{0}}{h_{01}}\right]^{\gamma /(\gamma-1)}
$$

$\eta_{\mathrm{s}, \mathrm{C}}:$ is the isentropic efficiency of compressor.

The velocity vectors and associated velocity diagram for

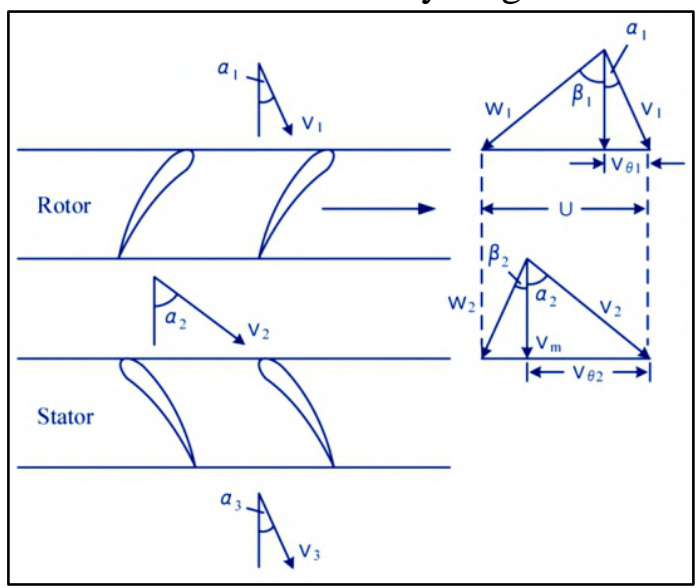

Fig. 9. Velocity and Angles for a Compressor Stage 


\section{Helium Turbine:}

The metal from which the turbine is made is a fixed ceramic type named CMCs. as shown in Figure 10. The turbine is light, pressure and heat resistant, lighter and more efficient, and can take aircraft longer distances without stopping and burning less fuel. Such as the LEAP engine and manufactured by the international CFM project, which is a joint venture between GE Aviation. While the turbine made is nickel-based materials for hot section are assumed. Nominal combustion temperatures of the mainburner and after-burner are set about $1700 \mathrm{~K}$ and $2000 \mathrm{~K}$, respectively. The low cycle pressure ratio simplifies the gas turbine mechanical design with optimum cycle without an intercooler.

Aviation. While the turbine made is nickel-based materials for hot section are assumed. Nominal combustion temperatures of the main-burner and after-burner are set about $1700 \mathrm{~K}$ and $2000 \mathrm{~K}$, respectively. The low cycle pressure ratio simplifies the gas turbine mechanical design with optimum cycle without an intercooler. Thermodynamic performance of the helium gas turbines is of critical concern as it considerably affects the overall cycle efficiency. Helium gas turbines pose some design challenges compared to steam or air turbomachinery because of the physical properties of helium and the uniqueness of the operating conditions at high pressure with low pressure ratio. The size of the blades in a helium turbine is around $0.1 \mathrm{~m}$ whereas the blades are larger than $1 \mathrm{~m}$ in the steam turbine [S. Takada, T. Takizuka, et al.,2003].

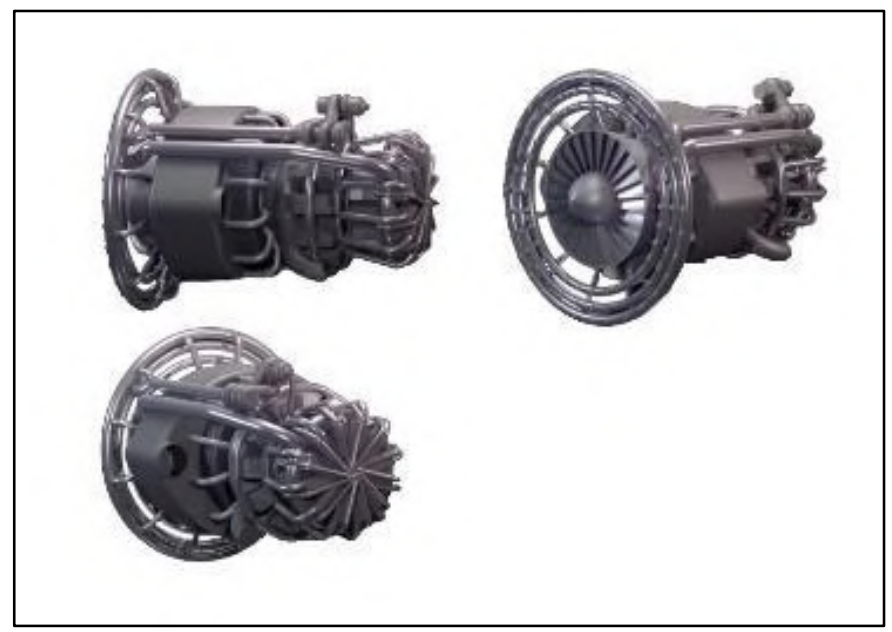

Fig. 10. Helium Turbine

Fig. 11 shows a typical axial-flow turbine stage. Similarly, the flow of a streamline enters the rotor at one radius and leaves at another radius with another velocity. The change in angular momentum in passing the rotor comes from the enthalpy decrease [H.I.H. Saravanamuttoo, G.F.C. Rogers and H. 
Cohen,2001]. The process through the rotor and stator is adiabatic, and the stagnation pressure decreases in the stator due to fluid friction. There is a decrease in stagnation pressure only within the rotor. There is no work in the stator and hence the stagnation temperatures of positions 1 and 2 are the same. By applying the steady flow energy equation to the rotor, the power input is given by:

$$
P=\dot{m} C_{p}\left(T_{03}-T_{02}\right)
$$

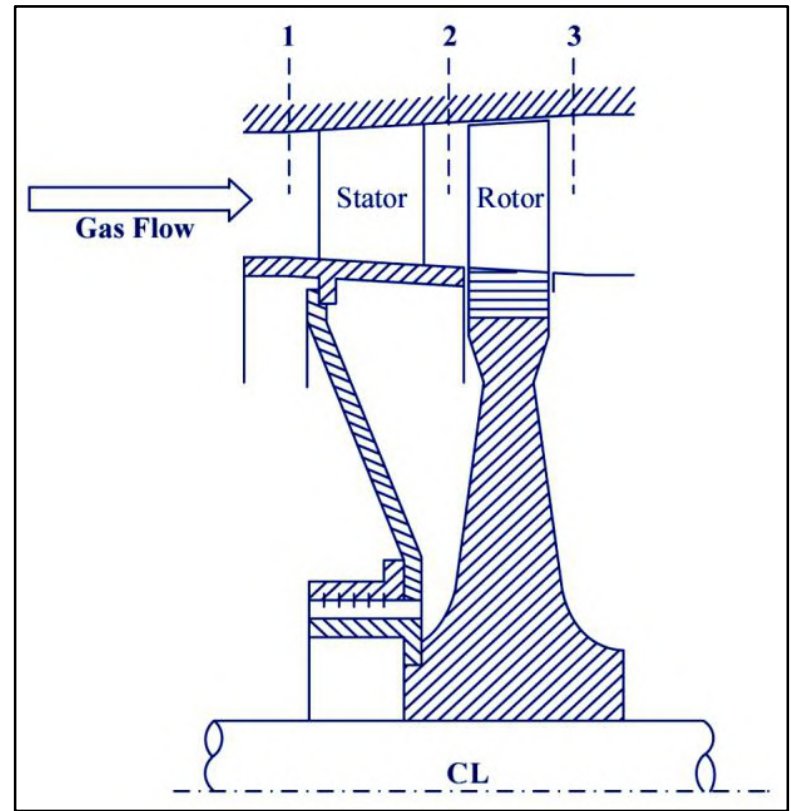

Fig. 11. Turbine flow Stage

The blade speed $U$ and the relative velocity $W_{2}$ at $\beta_{2}$. The fluid is deflected through the rotor and leaves the rotor with a relative velocity $\mathrm{W}_{3}$ at $\beta_{3}$, and the velocity $V_{3}$ is given at an angle $\alpha_{3}$. The tangential velocities $V_{\theta 2}$ and $\mathrm{V}_{\theta 3}$ are found from the meridional velocity $\mathrm{V}_{\mathrm{m}}$ and the flow angles, and these tangential velocities can produce work through the change in enthalpy. A decrease of total enthalpy is obtained from the Euler turbomachine equation along the streamlines. Fig. 12.

$$
\Delta h_{0}=\omega\left(r_{2} V_{\theta 2}-r_{3} V_{\theta 3}\right)
$$

The power input to the stage can be expressed as follows:

$$
P=\dot{m} \omega\left(r_{2} V_{\theta 2}-r_{3} V_{\theta 3}\right)
$$

This input energy is absorbed usefully in raising the pressure of the fluid, and the pressure rise is dependent on the efficiency of the compression process. The stagnation pressure ratio of the stage can be found from 


$$
\Delta T_{0 S}=\eta_{S, T} T_{01}\left[1-\left(\frac{1}{p_{01} / p_{03}}\right)^{(\gamma-1) / \gamma}\right]
$$

$\boldsymbol{\eta}$ S, T : is the isentropic efficiency of turbine.

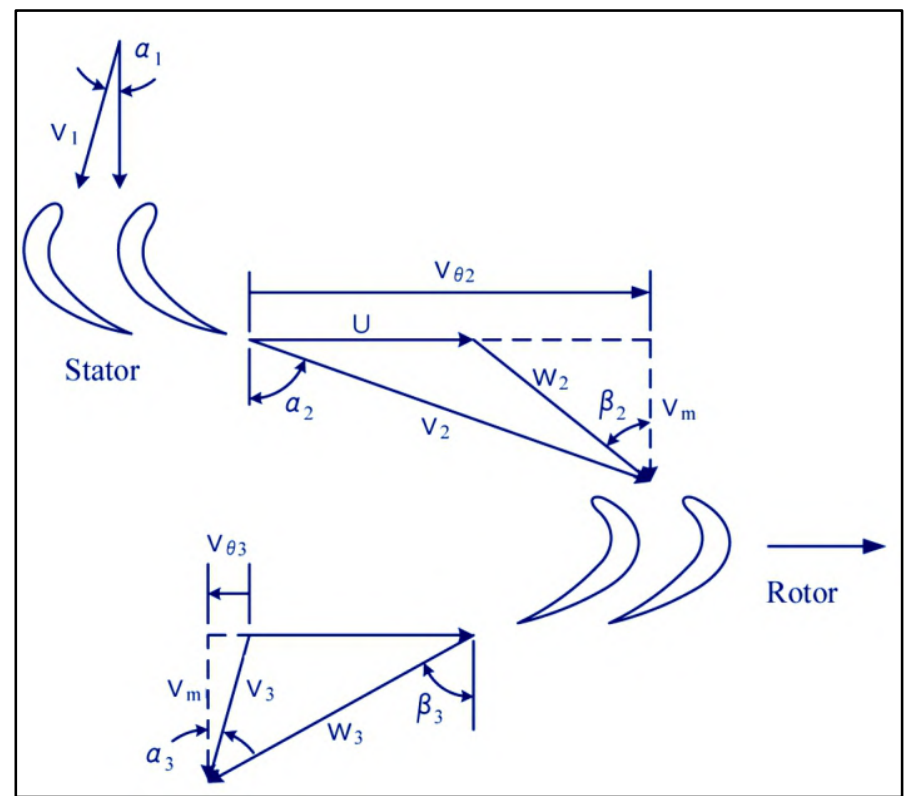

Fig. 12. Velocity and Angles for a Turbine Stage

\section{Ramjet (Bypass burners):}

The core SABRE engine is installed in a nacelle. The design of this nacelle is such that at the end of the air-breathing phase (Mach 5 and $26 \mathrm{~km}$ altitude) Fig. 13, the air swallowed by the nacelle inlet is equal to the required air consumption of the core SABRE engine. The hydrogen flow rate at this point leads to a very fuel rich engine mixture ratio as a significant fuel flow is required in order to maintain the inlet pre-cooler heat exchanger performance.

At lower altitudes it follows that, due to increased atmospheric density, the captured airflow exceeds the demand of the core engine.

The nacelle is therefore designed to bypass the excess air around the core engine. If this is done with no further action, a significant drag penalty is incurred as the excess air swallowed has lost a significant amount of relative momentum. As a result, the engine utilises a system of bypass burners arranged circumferentially around the core engine to add additional energy to the bypass airflow and recover the lost momentum. As the core engine runs fuel rich in order to maintain its cooling performance there is, conveniently, an excess of hydrogen fuel available with which to achieve this.

The bypass burners themselves are segmented which would be a standard approach based on jet engine heritage. However; the operation is 
quite lean and the range of lean operation is significant. This is addressed by a two zone combustion approach where the fuel is injected rich in the primary zone at relatively constant conditions and diluted further in the secondary zone depending on the overall airflow. The detail at this level needs to be filled in as there is some novelty and significant design work foreseen. [SKYLON,2011]. the bypass fan windmills and the bypass duct acts like a ramjet with steadily reducing flow up to Mach 5 when all the flow then passes through the core engine.

This is the direct opposite of a turbo-ramjet where the flow is steadily diverted from the core engine to the bypass ramjet system at the higher Mach numbers. The bypassed air is passed through a combustion system in the duct in order to heat the air and gain thrust from it during supersonic acceleration. It is in effect a bypass ramjet, the thrust from which falls to zero at the engine design operating condition. In particular the installation must include a bypass duct so that excess capture flow beyond that required by the core engine can be conducted to the bypass nozzle without passing through the core engine cycle.

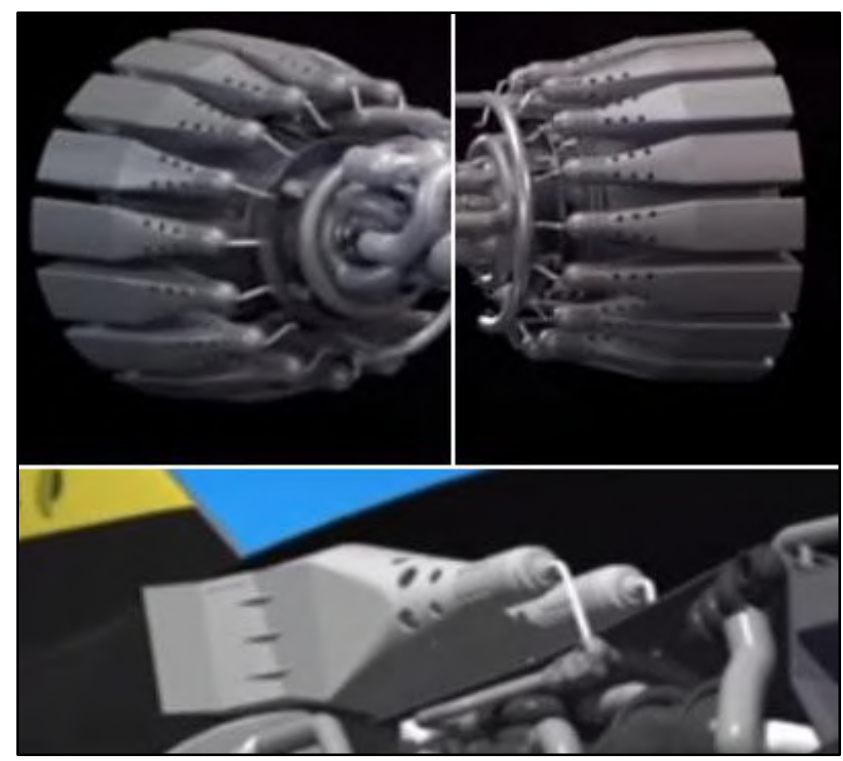

Fig. 13 Bypass burners

\section{Engine nozzles}

One being the nozzle design and performance. Fig. 14, as described above, engine has two nozzles, one for the bypass and the other for the core engine. For efficient operation it is essential that these nozzles have the correct throat area to pass the flow under the upstream pressure and temperature conditions, and the correct exit area to expand them efficiently to prevailing ambient conditions. The engine poses several design and development 
challenges in intakes, nozzles, although none of these require fundamental breakthroughs in technology for their realisation. The installation of the engine has In particular the installation must include a bypass duct so that excess capture flow beyond that required by the core engine can be conducted to the bypass nozzle without passing through the core engine cycle.

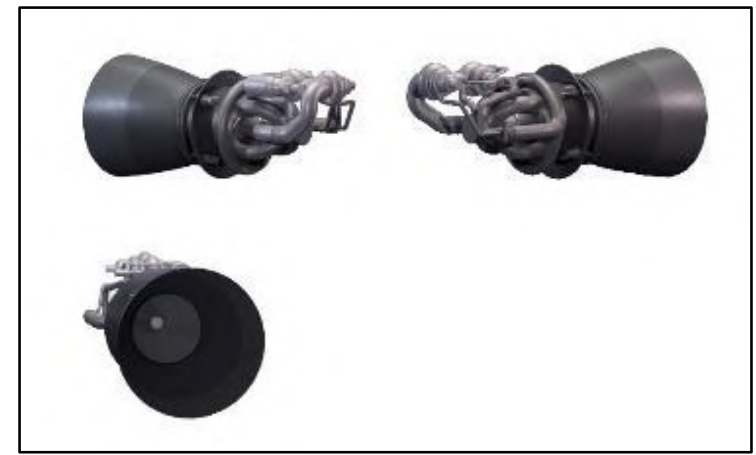

Fig. 14 nozzle engine and provides thrust in air-breathing

One of the difficulties, in a conventional nozzle the high pressure gasses, which are a product of the combustion, are accelerated through the nozzle and, in this process, the pressure is reduced. The higher the final velocity: the higher the engine performance, for a given chamber and propellant. Higher velocities are achieved by increasing the ratio of the nozzle exit area to throat area. The force thrust chamber in air-breathing for exhaust nozzle can be expressed as follows:

$$
\text { Thrust }=\mathrm{F}=\mathrm{m}^{\bullet} \mathrm{V}_{\mathrm{e}}+\left(\mathrm{P}_{\mathrm{e}}-\mathrm{P}_{\mathrm{o}} \mathrm{A}_{\mathrm{e}}\right.
$$

The mass flow rate $\mathrm{m}^{\bullet}$, velocity $\mathrm{V}$, pressure $\mathrm{P}$ and Area $\mathrm{A}$ as show Fig. 15.

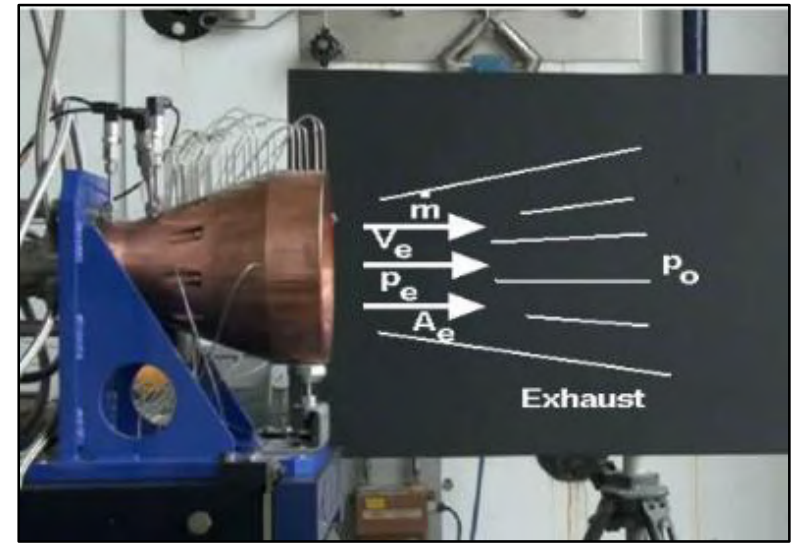

Fig. 15 Strict Engine Test Firing

\section{Propellant Tanks}

The liquid hydrogen (LH2) and liquid oxygen (LOX) tanks are effectively one joined tank, separated by insulation. The LH2/LOX tanks are 
an unsupported structure, relying on an internal pressure of approximately 2 bar (absolute) on ground to maintain structural integrity during handling. The mission pressure schedule is designed to maintain a 1 bar delta $\mathrm{P}$ ( 2 bar absolute at ground roll). Boost pumps are used to empty tanks prior to re-entry. The tank pressures are managed for this phase by control of venting via a relief valve system.

\section{Engine testing}

In principle all types of Air-breathing engine (Turbojets, ramjets, scramjets) offer a significant performance increase over rockets. This is of course because only the stored fuel mass is significant for performance for the Air breathing part of the engine operation. The traditional downside with these types of engines are twofold, firstly that traditional air breathers only operate across a limited Mach number range. For example scramjets need to be accelerated up to speeds of at least Mach 4 before they can operate. This leads to expensive ground test facilities or in-flight testing only. The second issue with traditional air breathing concepts is that they have very low thrust to weight ratios. Thus for any launcher employing these engines the inert mass of the launcher (non-payload mass carried into orbit) must also increase. The SABRE engine whilst having a performance (ISP or specific fuel consumption) comparable to current scramjet concepts, has two distinct advantages, firstly that it can operate across the entire Mach range from 0 to Mach 6. This enables testing on the ground using established principles without recourse to expensive large scale wind tunnel or flight test facilities. As show Fig. 16 and Fig. 17.

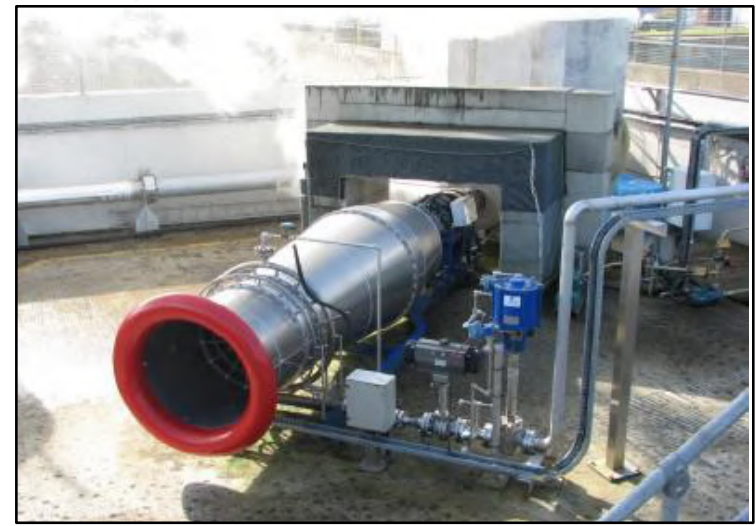

Fig. 16 the pre-cooler will be tested at RELS B9 Test site using a VIPER 522 jet engine 


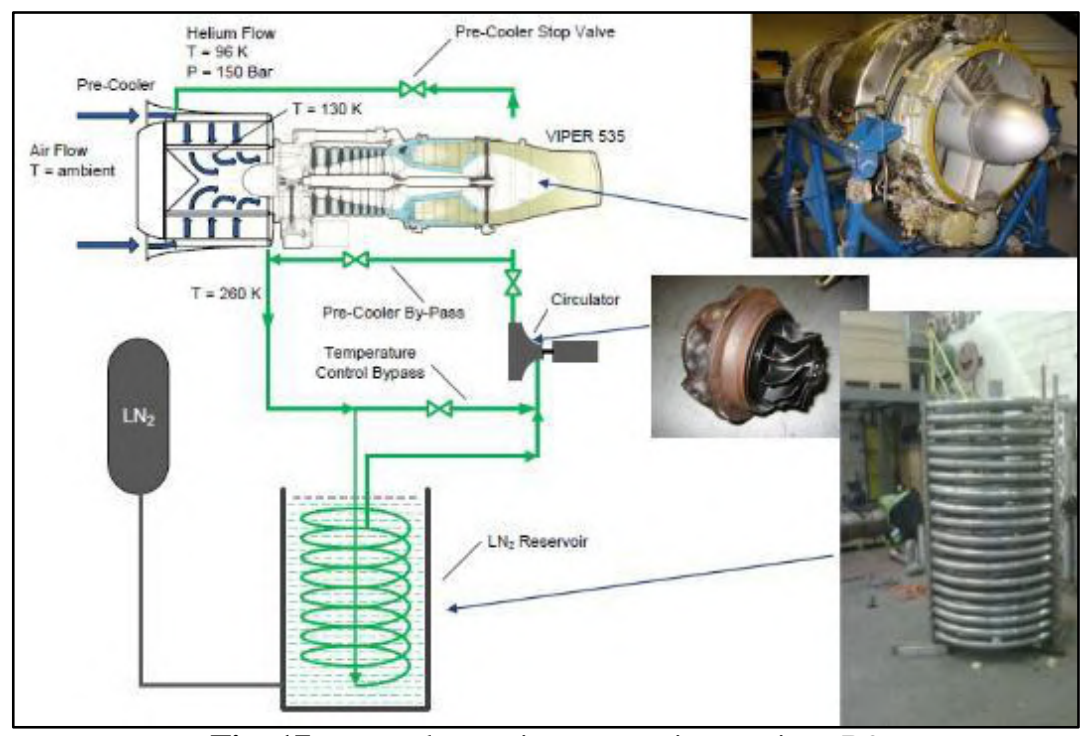

Fig. 17 pre-cooler testing at reaction engines B9

Secondly it has a high thrust to weight ratio in comparison to other air breathing concepts. RD14 states that it is these two factors - Competitive ISP for high Mach number operation performance, coupled with high thrust to weight ratio which makes the engine competitive for SSTO applications (refer to figures 18 and 19).

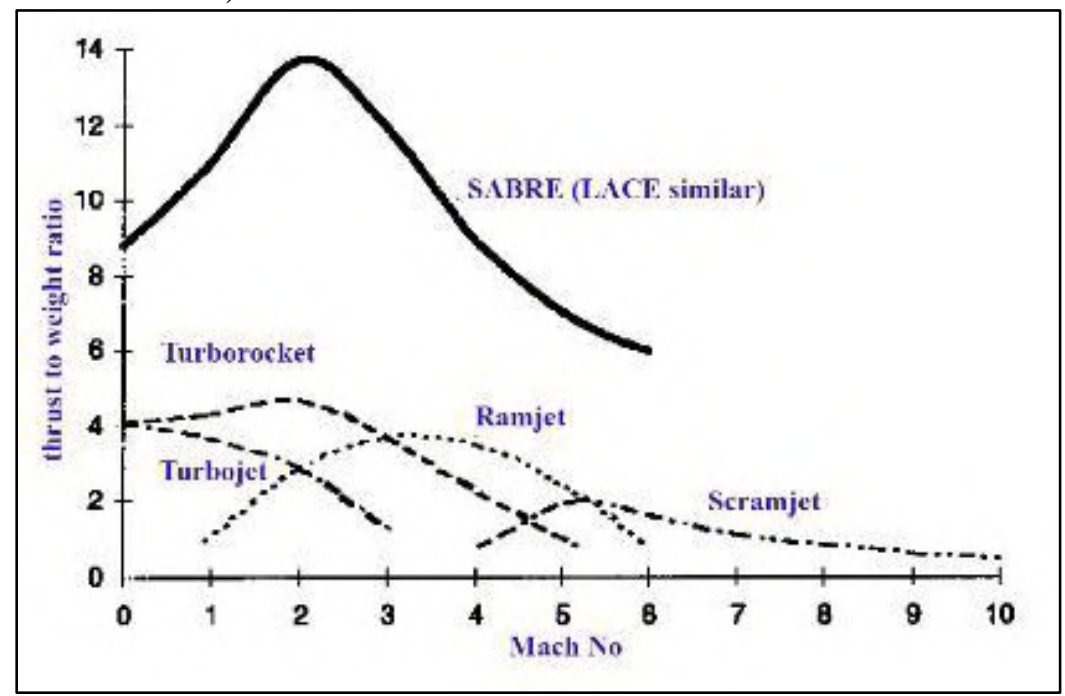

Fig.18 SABRE thrust to weight ratio vs Mach no. (RD14) 


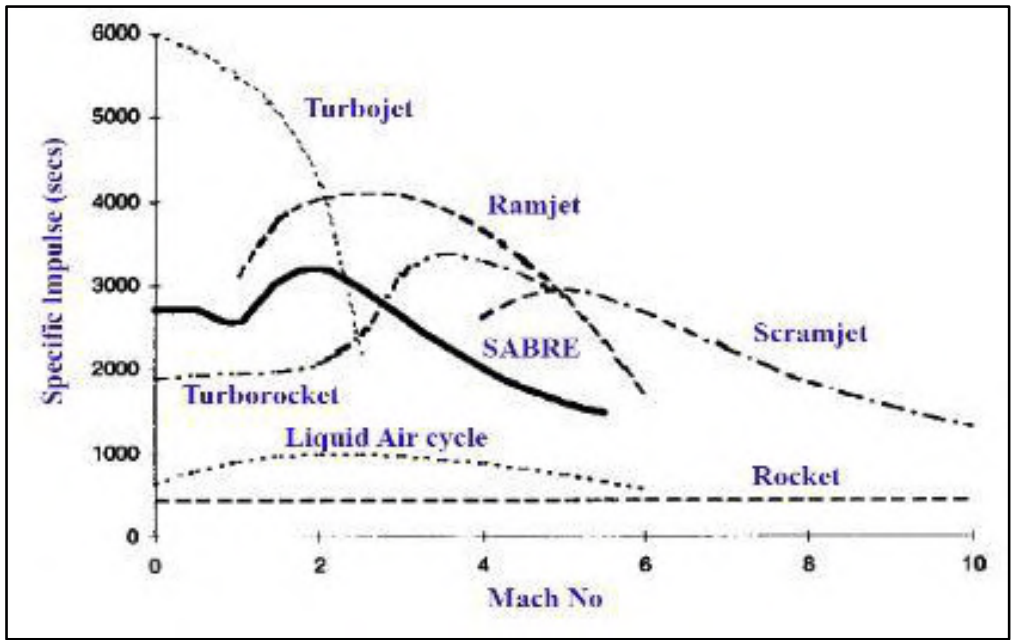

Fig.19 SABRE ISP vs Mach number (RD14)

\section{Heat Exchangers}

The precooler is thus split into two parts. At the hot end anonisentropic counter flow heat exchanger with a capacity ratio of 3 is used in order to counteract the entropy rise due to the hot end temperature limitation of the precooler. T2, as indicated in Fig. 20 and Fig. 21, is the resulting cold end temperature of the non-isentropic counter flow heat exchanger. The remaining heat in the external air flow can then be removed using a low temperature heat exchanger that is not constrained by material temperature limitations and can therefore operate closer to isentropic conditions. Figure 21 illustrates the initial counter flow heat exchanger using an increased capacity rate ratio (K1) followed by a capacity matched counter flow heat exchanger (K2).

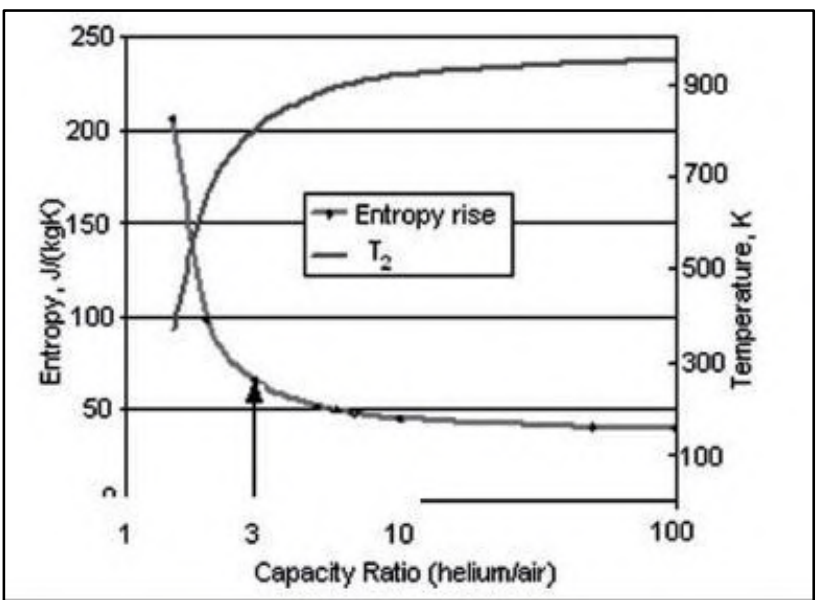

Fig 20. The Effect of helium to air capacity ratio on entropy generation in a counter flow heat exchanger with air inlet temperature of $1240 \mathrm{~K}$ and helium exit temperature of $950 \mathrm{~K}$, and where $\mathrm{T} 2$ is the cold end temperature of both streams assuming no $\Delta \mathrm{T}$. 


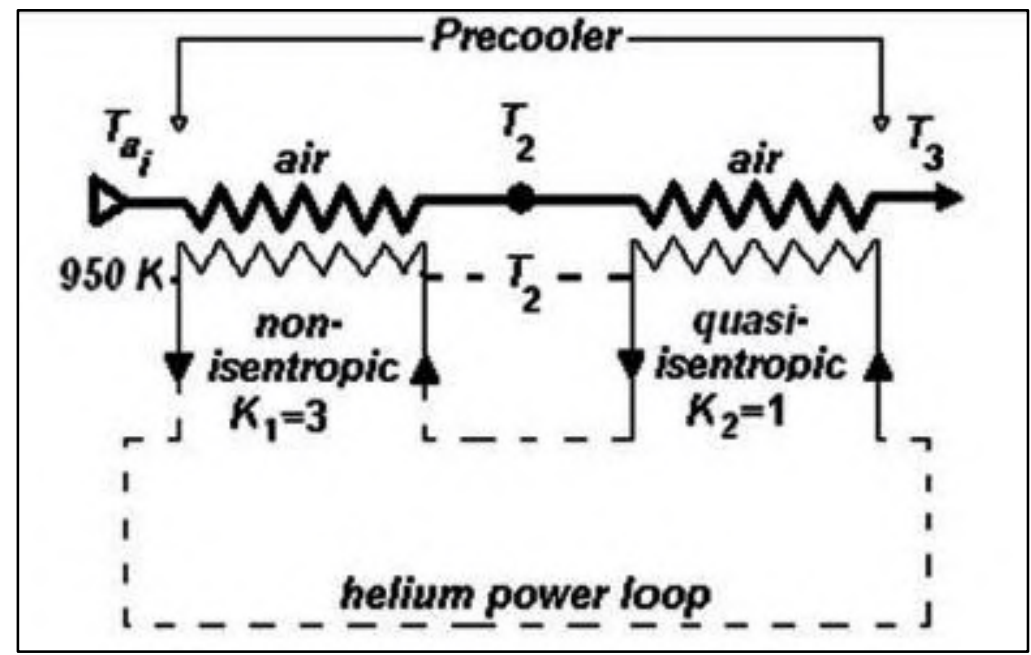

Fig. 21 Precooler thermodynamics; $\mathrm{K}$ in this case Is the helium to air capacity ratio

For the precooler capacity matched counter flow heat exchanger (see Fig. 22) where $\mathrm{C}$ is the capacity rate

$$
m c_{p}
$$

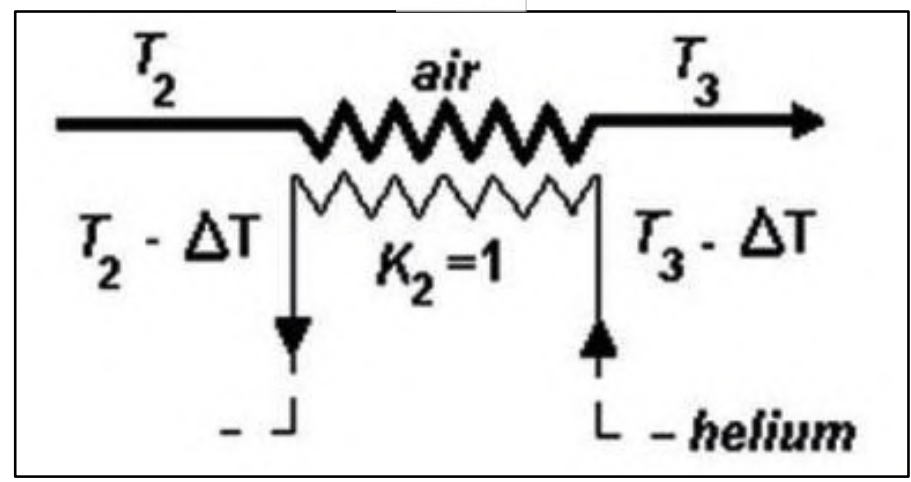

Fig.22 Precooler low temperature, capacity matched heat exchanger

Of either the air or helium stream, the entropy rise per unit capacity rate

$$
\frac{\Delta S}{C}
$$

Assuming no pressure loss is given by:

$$
\frac{\Delta S}{C}=\ln \left(\frac{T_{3}}{T_{2}}\right)+\ln \left(\frac{T_{2}-\Delta T}{T_{3}-\Delta T}\right)
$$


Assuming a $\Delta \mathrm{T}<<\mathrm{T}_{2}, \mathrm{~T}_{3}$, Equation (12) can be reduced to:

$$
\frac{\Delta S}{C} \approx \frac{\left(T_{2}-T_{3}\right)}{T_{2} T_{3}} \Delta T
$$

The entropy increase of the precooler low temperature heat exchanger is therefore proportional to the finite temperature difference, $\Delta \mathrm{T}$, between the hot air stream and helium coolant stream. The enthalpy and entropy balance of the air and hydrogen streams as outlined in Fig.23.

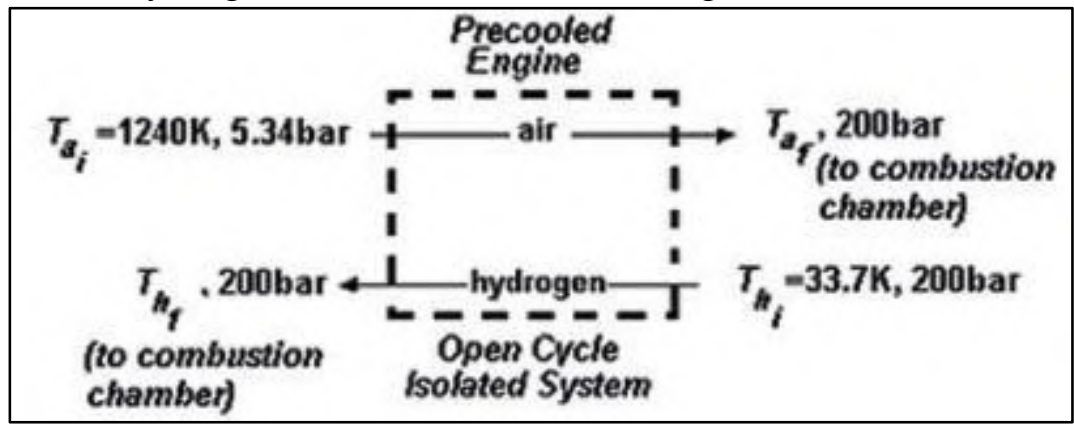

Fig.23 Black box precooled engine cycle diagram

And assuming no pressure loss within the hydrogen stream, the maximum achievable air pressure ratio

$$
\frac{P_{a_{f}}}{P_{a_{i}}}
$$

Where Pressure Air Final $\mathrm{P}_{\mathrm{a} f}$ and the pressure Air Initial $\mathrm{P}_{\mathrm{ai}}$ is defined by:

Since

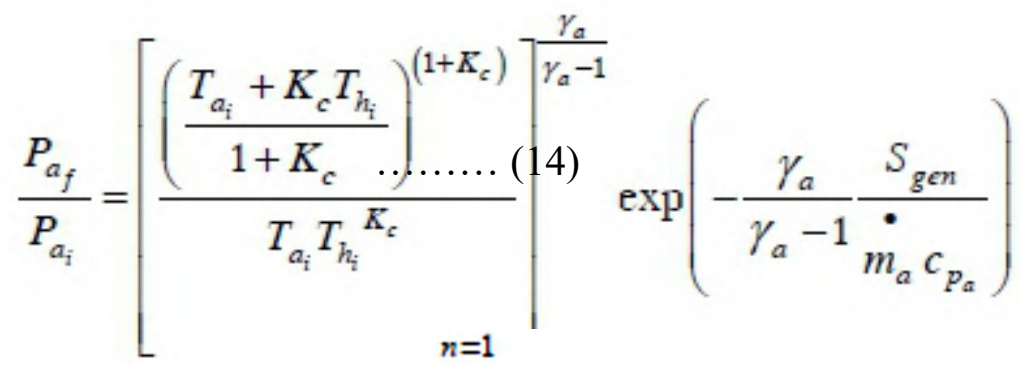

$$
S_{g e n}=\sum_{n=i}^{n=1} \Delta S_{i}
$$

Where $\Delta \mathrm{Si}$ is the entropy increase of a single component in the engine cycle, we can assess the sensitivity of each individual component's performance on overall cycle performance. Substituting Equation (14) into Equation (15) gives the engine cycle fuel/air capacity ratio, $\mathrm{K}_{\mathrm{c}}$ as a function of the low temperature heat exchanger $\Delta \mathrm{T}$ for a given air compression ratio. 
This is referenced to the $\Delta \mathrm{S}$ performance of the low temperature heat exchanger and the current fuel/air capacity ratio of 1.2 of SABRE [W.M. Kays and A.L. London, 1998].

The heat exchangers used within the SABRE cycle are fundamental to its success. While a great deal of attention has been focused on the pre-cooler, for obvious reasons, it is understood by ESA that the other heat exchangers HX3, 4 and 5 are also fundamental to the cycle and also require technology development. This said, very similar design, construction and manufacturing technologies are baselined in the $\mathrm{C} 1$ configuration mass estimations for the HX4 and HX5 units. HX3 should however be considered separately as there are some detail differences. As show Fig. 24.

The basic tube arrays, must be incorporated in large numbers and, though individual tubes prove to be very light, the total mass of the (approx. 300,000) tubes is significant. Achieving the required process control for manufacturing, both at individual tube level (drawing, subsequent cleaning and machining for reduction of the wall thickness) and during the integrations (bending soldering tooling and jigs), is a significant challenge but is addressed within the phase 1 and 2 activities.

The baseline heat exchanger designs for HX 4 and 5 are, from a construction standpoint, similar to $\mathrm{HX} 1$ and 2. Materials variations are employed but essentially metallic tube based heat exchangers are baselined and the manufacturing issues are the same as for HX1 and 2. Optional etched foil heat exchanger technology is also under examination at REL as a substitute for the current HX 4 design.

HX3 is an axial counter-flow heat exchanger sitting between the preburner and the chamber. Its purpose is top off and control the energy input into the helium power loop which is then used to run much of the turbo machinery (Turbocompressor or LOX pump). It is relatively compact based on the fact that both the helium and flow from the pre-burner arrive at high pressures with correspondingly good heat transfer coefficients. The efficiency of the design is not, in this case, paramount as there is considerable reserve energy left to be able to raise the helium temperature to the desired level and, when pre-cooling is fully operational at high Mach numbers, the heat transfer requirement is reduced.

Control of the $\mathrm{He}$ temperature rise across the pre-burner heat exchanger is indirect via the control of the pre-burner temperature. This is one key difference to the power-cycle of a conventional staged combustion approach in that the pre-burner has no direct link to the turbo-machinery [SKYLON,2011]. 


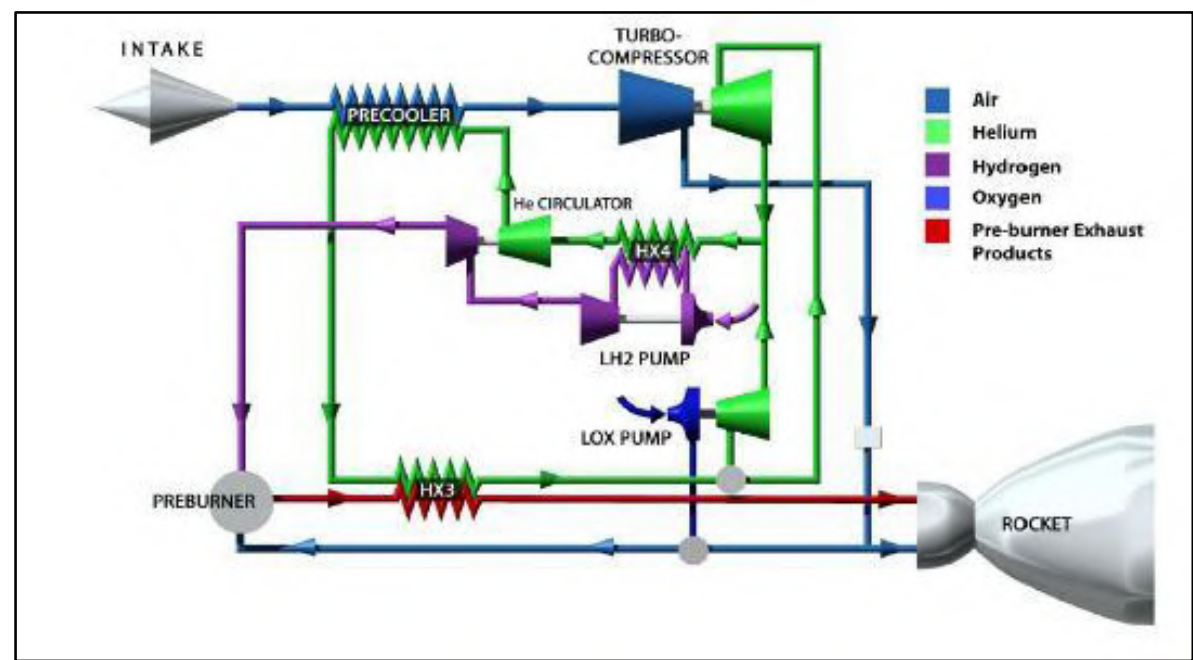

Fig.24 the Heat Exchangers cycle

\section{SABRE cycle work}

To allow the engine to use the superfast onrushing airstream as oxidiser, the air must be cooled from $1000^{\circ} \mathrm{C}$ to $-150^{\circ} \mathrm{C}$ within just a hundredth of second, at the same time avoiding the formation of dangerous ice.The temperature drop brings less compressor load. Then, the engine produces larger power compared to normal turbojet engines. The pre-cooler system is a high performance counter-flow heat exchanger consisting of thousands of small diameter tubes, arranged in involute spirals. The air flows radially inwards, whilst the helium coolant is introduced in the bore of the heat exchanger, and flows outwards along the spirals. This arrangement provides very high effectiveness ( $95 \%)$ with high heat transfer, minimising the size and mass of the heat exchanger.

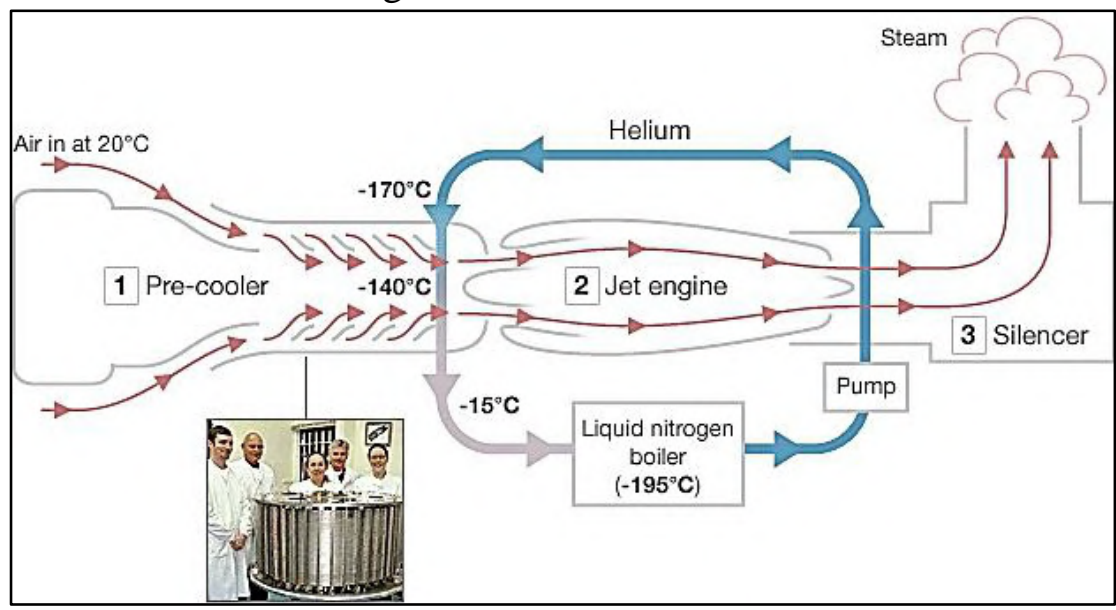

Fig.21 SABRE cycle 
Sabre would burn hydrogen and oxygen to provide thrust - but in the lower atmosphere this oxygen would be taken from the atmosphere. At high speeds, the engine is required to cope with 1,000-degree gases entering its intake. These have to be cooled prior to being compressed and burnt with the hydrogen.

REL's solution is a module containing arrays of extremely fine piping that can extract the heat and plunge the intake gases to minus $140 \mathrm{C}$ in just 1/100th of a second. Ordinarily, the moisture in the air would be expected to freeze out rapidly, covering the pre-cooler's pipes in a blanket of frost and dislocating their operation. But the company's engineers have also devised a means to stop this happening, permitting Sabre to run in jet mode for as long as is needed before making the transition to full rocket mode to take Skylon into orbit. It is the critical "pre-cooler" technology with its innovative helium cooling loop that REL is validating currently on an experimental rig at Culham.

\section{References:}

1. "Summary Report on Technical Experiences from High-Temperature Helium Turbomachinery Testing in Germany," IAEA-TECDOC-899, pp. 177-248, 1995.

2. Managing Director Dr. Alan Bond "Progress on the SKYLON Reusable Spaceplane in UK" pp.30, 8 December 2011

3. S. Takada, T. Takizuka, et al., "The 1/3-scale Aerodynamics Performance Test of Helium Compressor for GTHTR300 Turbo Machine of JAERI (STEP1)," Proceeding of ICONE11, Tokyo, Japan, April 20-23,2003.

4. A.R. Howell and W.J. Calvert, "A New Stage Stacking Technique for Axial-Flow Compressor Performance Prediction," Journal of Engineering for Power, Transactions of the ASME, Vol. 100, pp. 698$703,1978$.

5. T. Takizuka, S. Takata, et al., " $R \& D$ on the Power Conversion System for Gas Turbine High Temperature Reactors," Nuclear Engineering and Design, North- Holland Publishing Company, pp.329-346, 2004.

6. "Summary Report on Technical Experiences from High-Temperature Helium Turbomachinery Testing in Germany," IAEA-TECDOC-899, pp. 177-248, 1995.

7. Taguchi, H. and Yanagi, R., "A Study on Pre-Cooled Turbojet Scramjet-Rocket Combined Engines," AIAA-98-3777.

8. Hurst, J. N., et al., 1970, "Gas Turbomachinery for Helium Cooled Reactors," Proceedings of the British Nuclear Energy Society Conference on Nuclear Gas Turbines. London. April 8-9, 1970, pp 4350. 
9. International Atomic Energy Agency, 1988, "Gas-Cooled Reactor Coolant Circulator and Blower Technology," Proceedings No. IWGGCR/17. pp 1-164.

10. H.I.H. Saravanamuttoo, G.F.C. Rogers and H. Cohen, "Gas Turbine Theory, " Prentice Hall, 2001.

11. G.L. Dugger in W.H.T. Loh (Ed) "Jet, Rocket, Nuclear, Ion and Electric Propulsion; Theory and Design", Springer-Verlag, New York; 1968.

12. W.M. Kays and A.L. London, "Compact Heat Exchangers", Krieger Publishing Company, Florida, Reprint Edition with corrections, 1998.

13. Webber, H., Feast, S. and Bond, A., "Heat Exchanger Design in Combined Cycle Engines," IAC-08-C4.5.1, 2008.

14. SKYLON Assessment Report, European Space Agency (ESA), TECMPC/2011/946/MF (2011)

15. Taguchi, H. et. al., "Conceptual Study of Pre-Cooled Air Turbojet / Rocket Engine with Scramjet (PATRES), " ISABE 99-7024

16. Haselbacher, H., et al., 1978, "HHT Helium Turbine and the HHV Plant," Paper No. A4/21, presented at Nuclex 78, Basel, Switzerland, October 3-7, 1978. 